\title{
Correction of Severe Rotation of the Right Maxillary Central Incisor during the Permanent Dentition Period: A Case Report
}

\section{Vahid Mollabashi' ${ }^{1}$, Alireza Noorani²,*}

${ }^{1}$ Assistant Professor, Department of Orthodontics, Dental Research Center, Hamadan University of Medical Sciences, Hamadan, Iran

${ }^{2}$ Resident, Department of Orthodontics, Faculty of Dentistry, Hamadan University of Medical Sciences, Hamadan, Iran

* Corresponding Author: Alireza Noorani, Department of Orthodontics, School of Dentistry, Hamadan University of Medical Sciences, Hamadan, Iran. Email: Noorani_66@yahoo.com

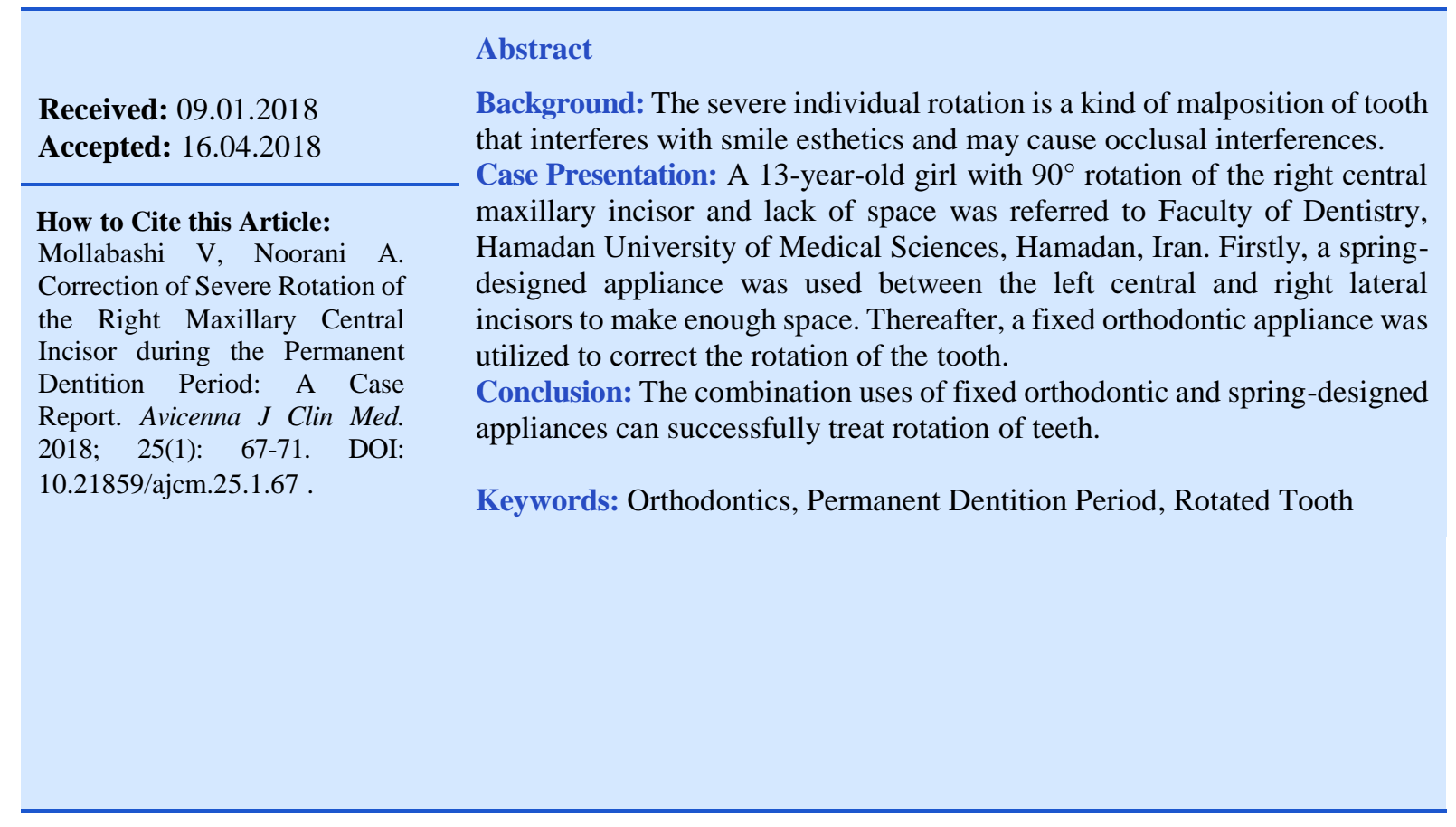


dof: $10.21859 /$ ajcm.25.1.67

\title{
كزارش يك مورد تصحيح جر خش شديد دندان ثناياى ميانى راست فك بالا در دوره دندانى دائمى
}

\author{
وحيد ملاباشى'، على رضا نورانى ז.* \\ ' استاديار ارتودنسى، مركز تحقيقات دندانيزشكى، دانشكاه علوم يزشكى همدان، همدان، ايران

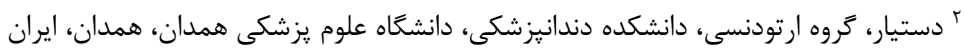 \\ * نويسنده مسئول: على رضا نورانى، كروه ارتودنسى، دانشكده دندانيزشكى، دانشعاه علوم يزشكى همدان، همدان، ايران.
}

ايميل: Noorani_66@yahoo.com

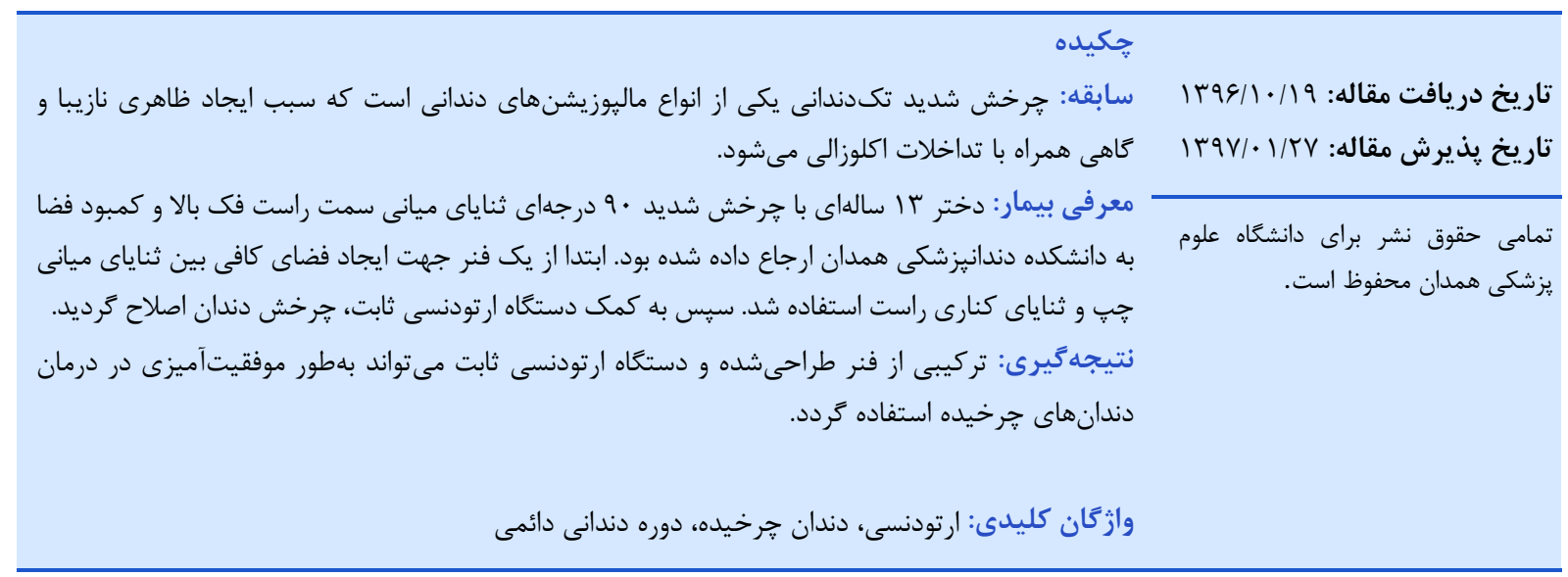

مقلهمه

دندان ثناياى ميانى راست بالا كه فضاى كافى براى اصلاح

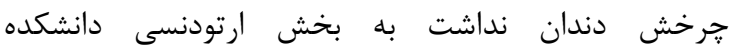

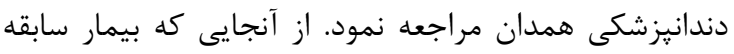

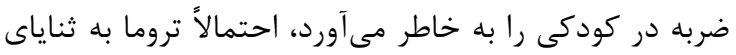
شيرى و جابهجايى جوانه دندان دائمى مذكور يا انكيلوز ثناياى

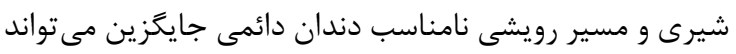

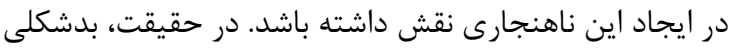

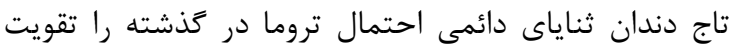

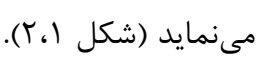

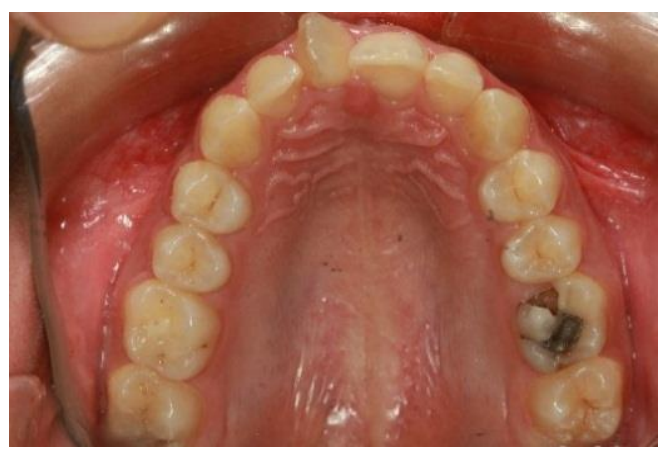

شكل ا: نماى اكلوزال فك بالاى بيمار
جرخش دندانى بلصورت جابهجايى قابل توجه داخل آلوئولى

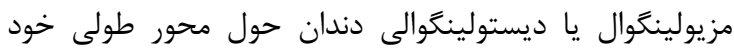

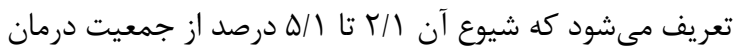

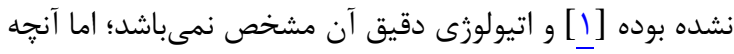
مسلهم است اين مال يوزيشنها همانند بسيارى از مال اكلوزنها تونها

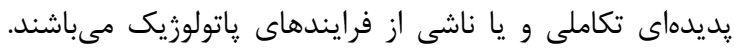

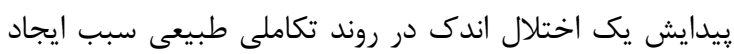

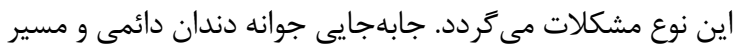

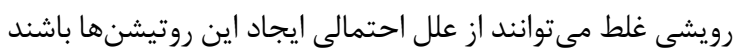
[ب]]. در عين حال، حضور دندانهاى اضافه در قدام ماكزيلا، تروما

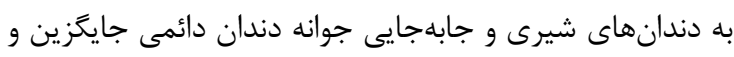

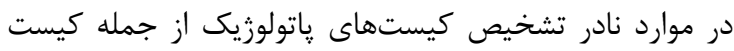

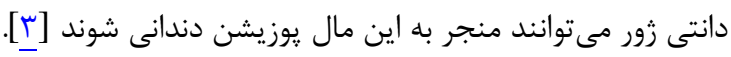
تصحيح جرخش تكىندان قدامى در صورتى كه همراه با مال يوزيشن دندانهاى مجاور و كمبود فضا در قوس باشد دشونى درارتر

خواهد بود [l].

معرفى بيمار

يك دختر با ساله با شكايت از جرخش شديد • و درجهاى 


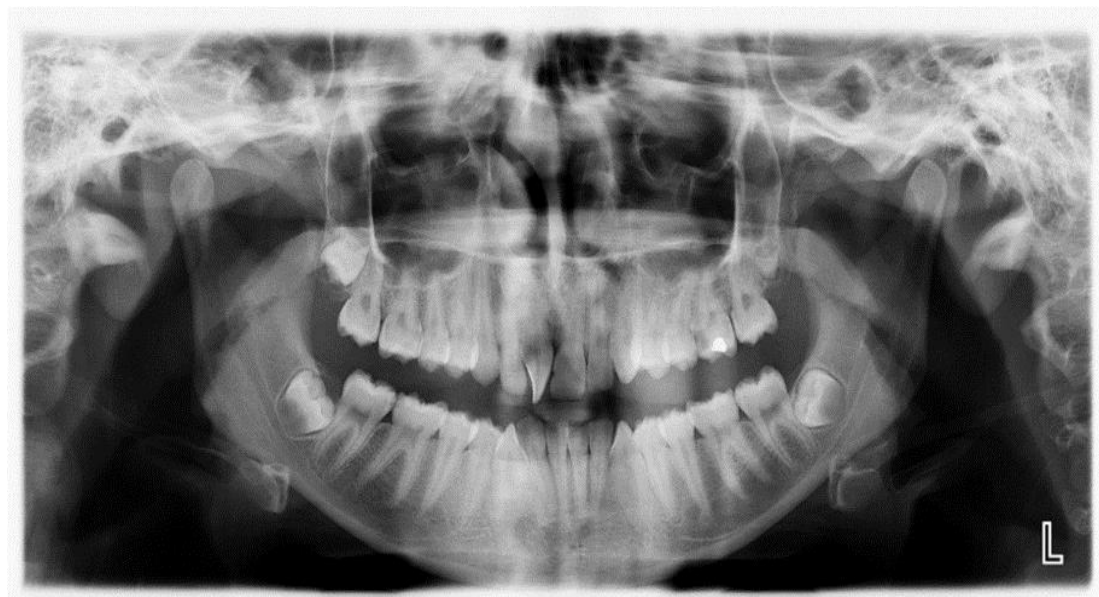

شكل r: نماى راديوكرافيك پانوراميك بيمار

از قراركيرى سيم Continuous مىشد. از سوى ديخر باكالى

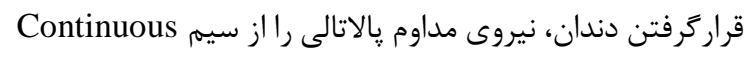

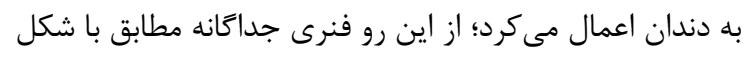

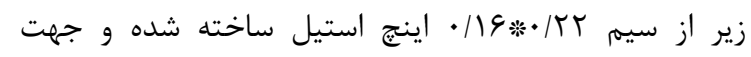

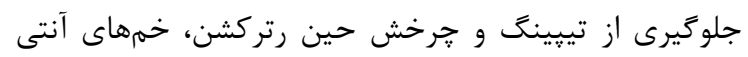

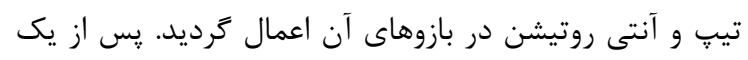

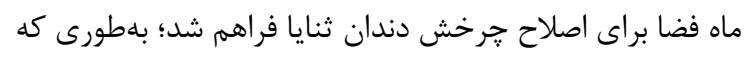

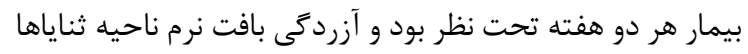

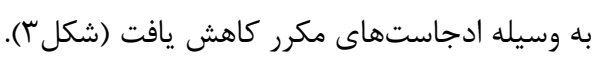

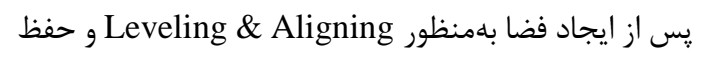

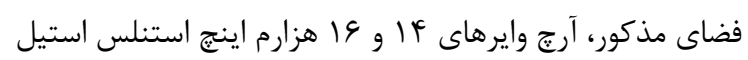

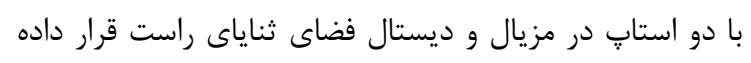

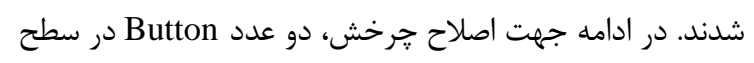

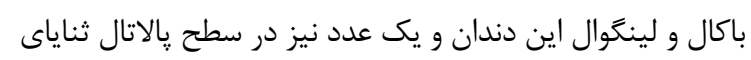

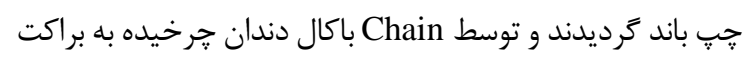

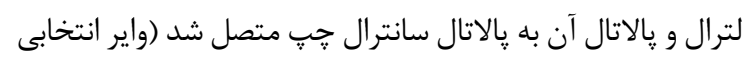

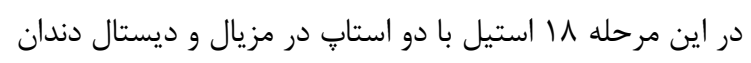

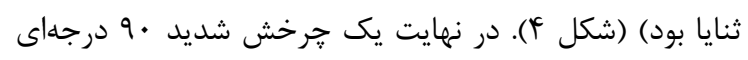

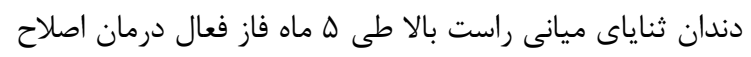

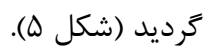

در معاينه كلينيكى صورت بيمار سيمتريك، ارتفاع آن نرمال

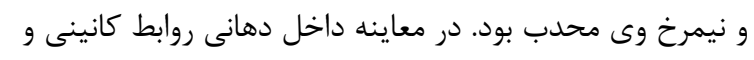

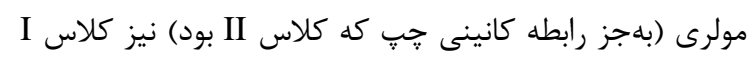

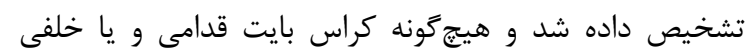

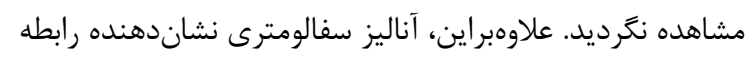

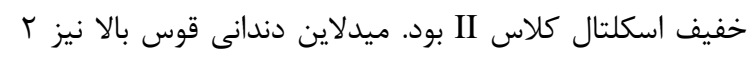
ميلىمتر به سمت راست منحرف شده بود؛ درحالى كالى كه ميدلاين بلاين يايين نرمال بود. - ميله

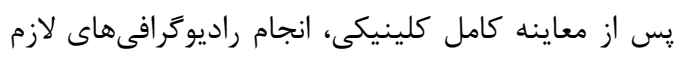

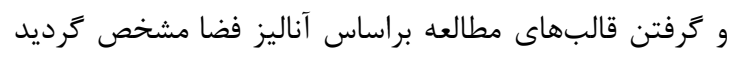

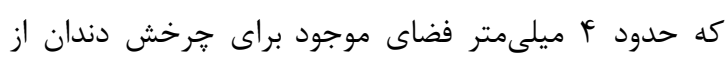

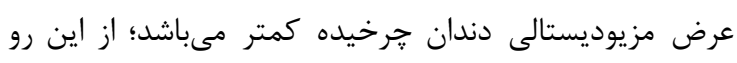

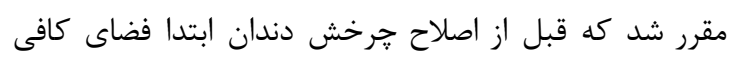

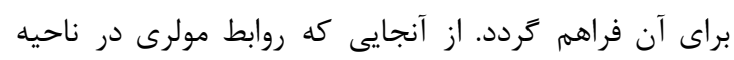

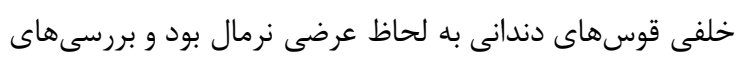

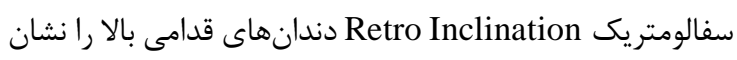

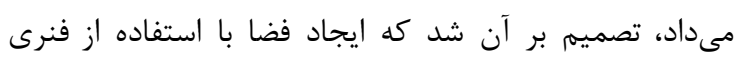

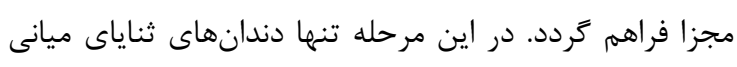

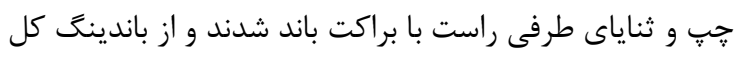

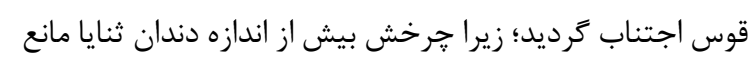

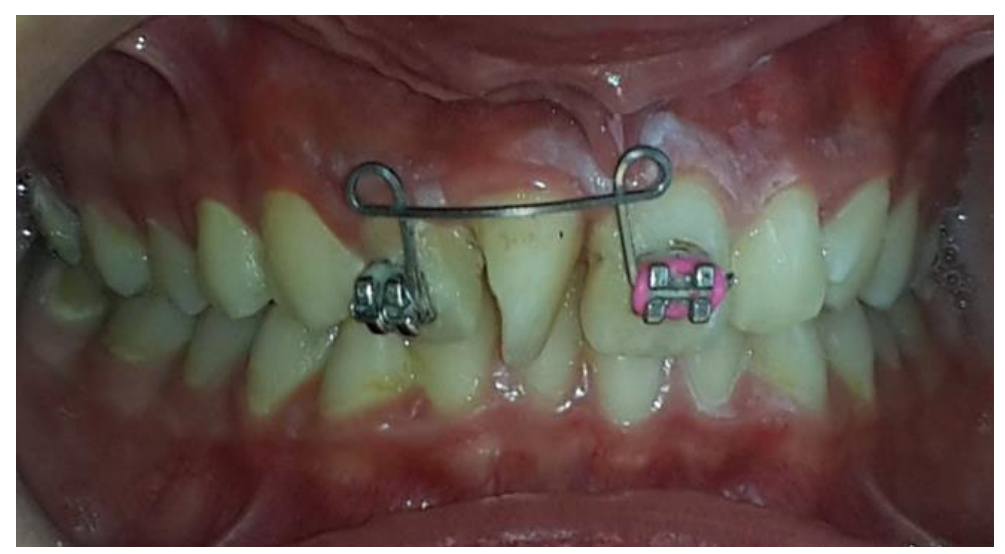

شكل ؟ّ: فنر طراحىشده از نماى روبهرو 


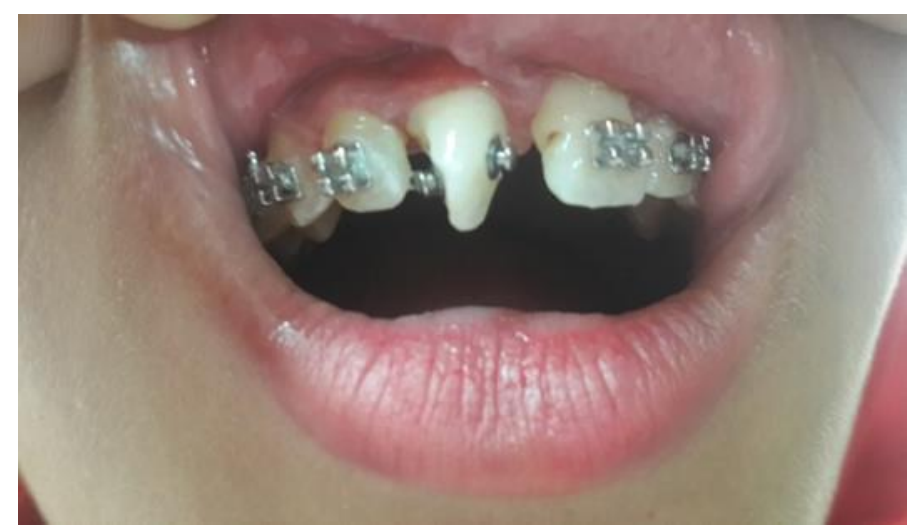

شكل fأ نماى روبهرو از دندان ₹رخيده يس از ايجاد فضا

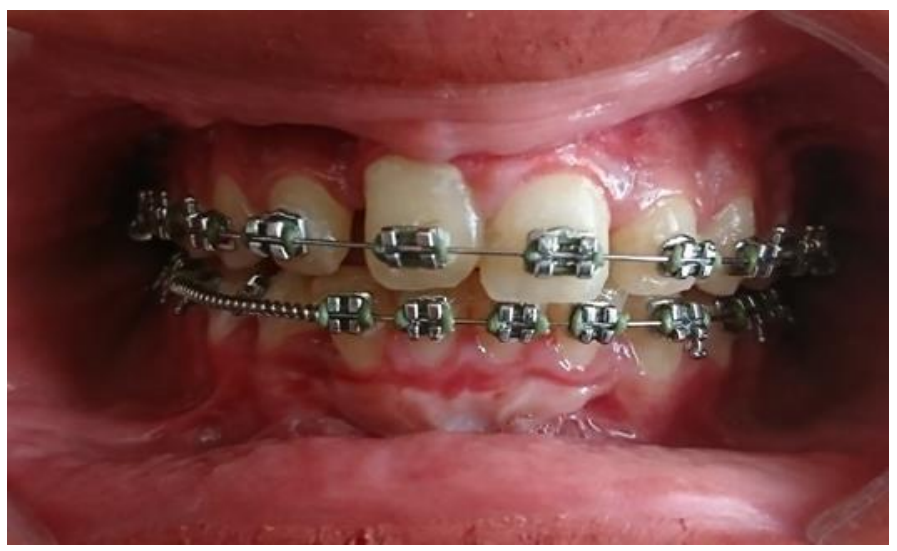

شكل ه: نماى نهايى پس از اصلاح جرخش دندان

تنها بر روى دندانهاى ثناياى ميانى جֶ و ثناياى طرفى راست

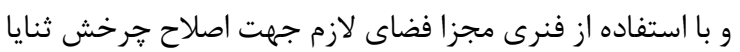
فراهم شود و از باندينگ كل قوس اجتناب كردد.

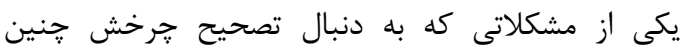

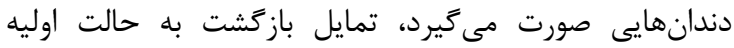

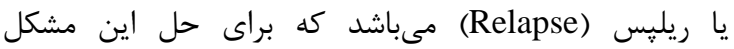

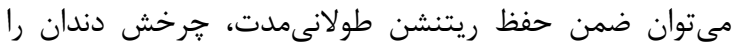

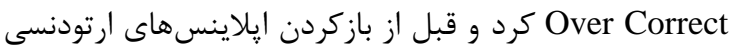

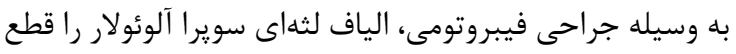
نمود [ه]. در انتها و يس از اصلاح جرخش، بيمار به بخش جراحى لثه

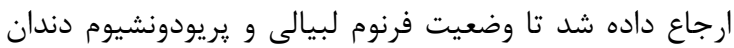

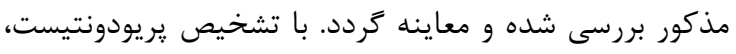

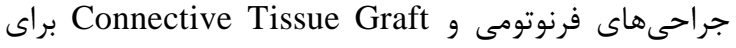

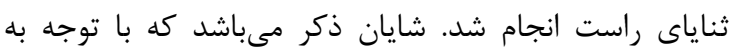

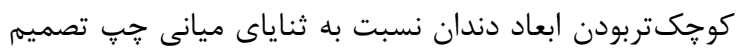

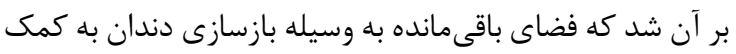
مواد ترميمى بسته شود.
با درمان اين نوع جرخشهاى تكىندانى مى توان از صدمات

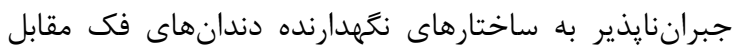

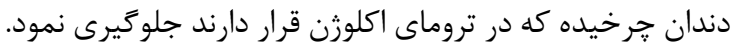

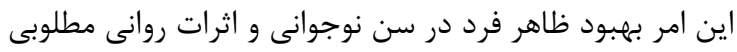

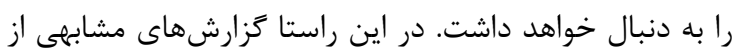

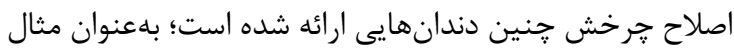

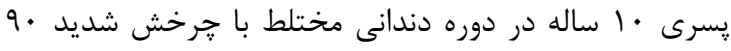

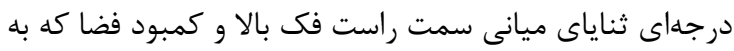

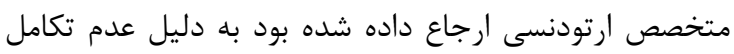

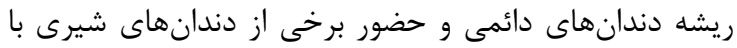

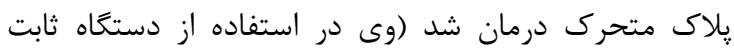

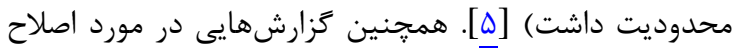

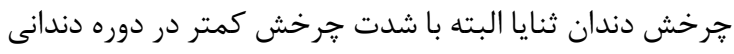

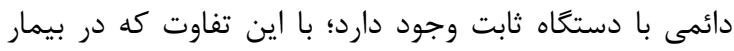

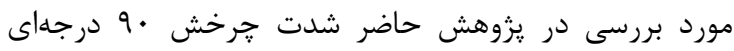

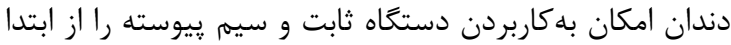
فراهم نمى كرد و سن تكاملى و وضعيت اجتماعى بيمار اجازه

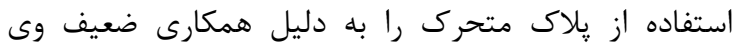

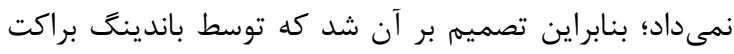




\section{REFERENCES}

1. Shpack N, Geron S, Floris I, Davidovitch M, Brosh T, Vardimon AD. Bracket placement in lingual vs labial systems and direct vs indirect bonding. Angle Orthod. 2007; 77(3):509-17. PMID: 17465662 DOI: 10.2319/00033219(2007)077[0509:BPILVL]2.0.CO;2

2. Houston W, Isaacson K. Orthodontic treatment with removable appliances. $2^{\text {nd }}$ ed. Bristol: John Wright \& Sons; 1980.

3. Singh RA, Vineet D, Amish D. Eruption disturbance of permanent central incisor caused by mesiodentes--a case report. J Oral Health Res. 2011;2(2):51-5.

4. Sidiq M, Yousuf A, Bhat M, Sharma R, Bhargava N, Ganta $\mathrm{S}$. Correction of a severely rotated maxillary incisor by elastics in mixed dentition complicated by a mesiodens. Int J Clin Pediatr Dent. 2015;8(3):234-8. PMID: 26604544 DOI: 10.5005/jp-journals-10005-1320

5. Jalali T, Bagherian A. Combination of removable appliance with whip spring in the treatment of severely rotated maxillary central incisor in the mixed dentition: a case report. J Mashhad Dental Sch. 2006;30:161-6. [Persian] 